\title{
Prevalence of neurological disorders in Al Quseir, Egypt: methodological aspects
}

This article was published in the following Dove Press journal:

Neuropsychiatric Disease and Treatment

7 September 2013

Number of times this article has been viewed

\author{
Hamdy El-Tallawy' \\ Wafa Farghaly' \\ Nabil Metwally ${ }^{2}$ \\ Tarek Rageh' \\ Ghaydaa A Shehata' \\ Reda Badry' \\ Esam El Moselhy ${ }^{2}$ \\ Mahmoud Hassan ${ }^{2}$ \\ Mohamed M Sayed ${ }^{3}$ \\ Ahmed A Abdelwarith' \\ Y Hamed ${ }^{2}$ \\ I Shaaban ${ }^{2}$ \\ Talal Mohamed ${ }^{4}$ \\ Mohamed Abd El Hamed' \\ MR Kandil' \\ 'Department of Neurology, Faculty \\ of Medicine, Assiut University, Assiut, \\ Egypt; ${ }^{2}$ Department of Neurology and \\ Public Health, Faculty of Medicine, \\ Al-Azhar University (Assiut branch), \\ Assiut, Egypt; ${ }^{3}$ Department of \\ Neurology, Faculty of Medicine, Sohag \\ University, Sohag, Egypt; ${ }^{4}$ Department \\ of Neurology, Faculty of Medicine, \\ Qena University, Qena, Egypt
}

Correspondence: Reda Badry Assiut University Hospitals, Neurology and Psychiatry Department, PO Box 71526, Assiut, Egypt $\mathrm{Tel}+2088236954$ I

Fax +20882351838

Email redaalbadry02@gmail.com

\begin{abstract}
Methodology and strategy play a very important role in epidemiological studies. Determination of the study area, geographical features, facilities, difficulties, and key personnel from the same area are important factors for successful methodology. Over 31 months (July 1, 2009 to January 31, 2012), a screening and an examination survey were carried out to ascertain the prevalence of epilepsy, stroke, dementia, cerebellar ataxia, migraine, cerebral palsy, Parkinsonism, chorea, athetosis, dystonia, trigeminal neuralgia, Bell's palsy, multiple sclerosis, spinal cord disorders, and attention deficit hyperactivity disorders in Al Quseir, Red Sea Governorate, Egypt. A total of 33,285 people were screened by three neurologists in a doorto-door manner, including every door, using a standardized Arabic questionnaire to detect any subject with a neurological disorder. The methodological aspects of this project were carried out through eight phases: (1) data collection; (2) preparation; (3) screening; (4) case ascertainment; (5) investigations; (6) classifications; (7) data entry; and (8) statistics and tabulations. The results of this study reveal that the total prevalence of neurological disorders in Al Quseir was 4.6\% and higher among females $(5.2 \%)$ than males $(3.9 \%)$. The highest prevalence was recorded in the elderly population (60+ years [8.0\%]) and among the age group $18-39$ years $(5.4 \%)$.
\end{abstract}

Keywords: methodological aspects, demographic data, prevalence

\section{Introduction}

Worldwide, epidemiological studies of neurological disorders are based mostly on hospital and autopsy records. ${ }^{1}$ These studies are somewhat biased, particularly in developing countries, in which not all the population has access to the public health system and no mandatory reporting practice exists. ${ }^{2}$ Screening and examination surveys conducted in a door-to-door manner have proved useful for investigating the prevalence of major neurological disorders. ${ }^{3}$

Disorders of the nervous system are important causes of mortality and morbidity around the world. However, current knowledge on risk factors and epidemiology of such conditions is mostly based on North American or European studies, and little data from developing countries have been published. ${ }^{4}$ Prevalence studies provide pertinent epidemiological data for a rational approach to planning health care provision, as well as providing a basis for hypothesis generation in clinical research or analytical epidemiological studies. ${ }^{5}$

The aim of this study was to design a strategy and methodological aspects for evaluation of the prevalence of major neurological disorders in the city of Al Quseir, Red Sea Governorate, Egypt. 


\section{Population and methods Population}

The project was carried out on eligible inhabitants who had been living in Al Quseir city for at least 6 months at the time of study. The study was carried out under the supervision of the Faculty of Medicine, Assiut University, Assiut, Egypt.

\section{Study area}

The Red Sea Governorate is the longest governorate in Egypt. All its cities and villages lie directly on the Red Sea within a distance of around $1080 \mathrm{~km}^{2}$, and its surface area is about $119,000 \mathrm{~km}^{2}$. There are six cities in the Red Sea Governorate: Ras Gharib, Hurghada, Safaga, Al Quseir, Marsa Alam, and Shalatin. ${ }^{6}$

Al Quseir city is the second largest city in terms of population size and has a great military and commercial history and a large citadel. ${ }^{6}$ Nonresponsiveness was expected to be high in this locality; extra effort was made to minimize this according to the methods of El Tallawy et al. ${ }^{7}$

\section{Methods}

The research team, consisting of three qualified neurologists, had their work supervised by the staff members of Assiut University. Fifteen female social workers collected demographic data.

The time schedule for this project extended from July 1, 2009 to January 31,2012 , and comprised the following phases:

1. Data collection (July 1 to December 31, 2009). Information about the population, geography, and facilities and difficulties of the study area was collected.

2. Preparation phase (January 1 to May 31, 2010). Through this phase, the questionnaire (Figure S1) and detailed data sheets for the included neurological disorders were prepared and fully discussed by supervised staff members and three neurology specialists.

3. Screening, case ascertainment, investigations, and classification of the included neurological disorders (June 1 to June 30, 2011).

4. Data entry (June 15, 2010 to August 31, 2011).

5. Statistics and tabulation (September 1, 2011 to January 31, 2012).

6. Case ascertainment

7. Investigations

8. Classifications

\section{Demographics}

The total number of subjects was 33,285, of both sexes (49.4\% males and 50.6\% females). In total, $40.9 \%$ were married (40.7\% males and $41.1 \%$ females); $0.6 \%$ were divorced; $3.2 \%$ were widowed; and $22.9 \%$ (19.2\% males and $26.7 \%$ females) were single. Illiteracy was recorded in $9.7 \%$ (7.4\% males and $12.0 \%$ females), while $8.1 \%$ could read and write. Compulsory education (primary school) had been completed by $32.6 \%$, and higher education was recorded in $17.94 \%$.

\section{Included neurological disorders}

Fifteen neurological disorders were studied in this project: dementia, stroke, epilepsy, migraine, chorea, athetosis, dystonia, Parkinsonism, cerebellar ataxia, multiple sclerosis, spinal cord disorders, cerebral palsy, Bell's palsy, trigeminal neuralgia, and attention deficit hyperactivity disorders (ADHD).

\section{Ethics}

Informed written consent was obtained from the legal guardian in each subject's family, according to the ethics committee of Assiut University. In addition, written consent was obtained from the Egyptian Ministry of Health.

\section{Statistical analysis}

SPSS software (version 13; IBM Corporation, Armonk, NY, USA) was used for statistical analysis. Mean and standard deviation were calculated.

\section{Results}

Figure 1 illustrates the sample size, screened populations, and number of subjects who refused to participate. The study recorded 1,531 subjects with different neurological disorders, with a total prevalence of $4.6 \%$. Prevalence was higher in females $(5.2 \%)$ than in males $(3.9 \%)$. Age- and sex-specific prevalence is illustrated in Table 1.

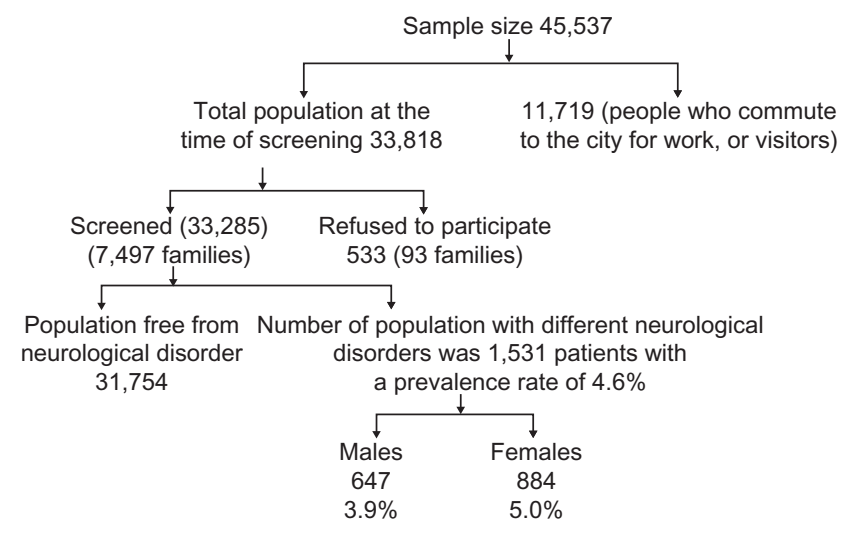

Figure I Algorithm of the project in Al Quseir, Red Sea Governorate, Egypt. 
Table I Age- and sex-specific prevalence of neurological disorders in Al Quseir, Red Sea Governorate, Egypt

\begin{tabular}{|c|c|c|c|c|c|c|c|c|c|}
\hline & \multicolumn{2}{|l|}{ Total } & \multirow[t]{2}{*}{$\mathrm{Cl}$} & \multicolumn{2}{|c|}{ Male } & \multirow[t]{2}{*}{ Cl } & \multicolumn{2}{|c|}{ Female } & \multirow[t]{2}{*}{ Cl } \\
\hline & $\mathbf{N}$ & $\%$ & & $\mathbf{N}$ & $\%$ & & $\mathbf{N}$ & $\%$ & \\
\hline$<18$ years & 419 & 3.5 & $2.66-4.58$ & 228 & 3.9 & $2.60-5.77$ & 191 & 3.1 & $2.10-4.53$ \\
\hline 18-39 years & 700 & 5.4 & $4.35-6.68$ & 225 & 3.4 & $2.19-5.19$ & 475 & 7.5 & $5.89-9.49$ \\
\hline $40-59$ years & 244 & 4.0 & $3.1-5.14$ & 88 & 2.9 & I.80-4.59 & 156 & 5.2 & $3.87-6.93$ \\
\hline $60+$ years & 168 & 8.0 & $6.7 I-9.50$ & 106 & 12.6 & $10.19-15.46$ & 62 & 5.0 & $3.70-6.71$ \\
\hline Total & $|, 53|$ & 4.6 & $4.38-4.83$ & 647 & 3.9 & $3.70-4.11$ & 884 & 5.2 & $4.77-5.24$ \\
\hline
\end{tabular}

Abbreviation: $\mathrm{Cl}$, confidence interval.

Table 2 illustrates the number of neurological disorders in subjects of different ages.

\section{Discussion}

This study is an extension of a series of projects aiming to study the epidemiology of major neurological disorders in northern Egypt (Assiut and Sohag districts as representative of all governorates in the Nile Valley and Al Kharga districts as representative of Egypt's west desert).

Three well-trained neurologists, 15 female social workers, a standardized questionnaire, detailed sheets for different neurological disorders, as well as supervision by nine staff members were the tools facilitating the methodology of this study.

Fifteen neurological disorders were evaluated in this study, yielding a prevalence of $4.6 \%$ (1,531 subjects out of 33,285 total population). The prevalence of different neurological disorders was higher among females, at $5.2 \%$ (884 female subjects out of 16,857), than in males, at 3.9\% (647 male subjects out of 16,428).

The highest prevalence of neurological disorders was recorded among elderly ( $\sim 60$ years), at $8.0 \%$, and was higher among males $(12.6 \%)$ than females $(5.0 \%)$ in this age group.

The prevalence of neurological disorders in Al Quseir $(4.6 \%)$ was higher than that found in other locations in other studies. Gourie-Devi et al found a prevalence of 3.1\% in Bangalore, India, ${ }^{8}$ and El Tallawy et al found a prevalence of $2.4 \%$ in Egypt's Al Kharga district. ${ }^{7}$ Meanwhile, Das et al reported that prevalence of neurological disorders among elderly in Kolkata, India was lower than that recorded in this study. ${ }^{9}$

The high prevalence of neurological disorders in this study area could be attributed to four factors: (1) lack of health services due to the absence of neurologists in Al Quseir; (2) increased prevalence of chronic diseases such as Parkinsonism, stroke, and cerebral palsy in comparison to worldwide data; (3) wide scope of neurological disorders included in this study; and (4) increased pollution by heavy metals in this area.

The second highest prevalence of the included neurological disorders among males (3.9\%) was recorded in childhood ( $<18$ years), which could be explained by the fact that most males at this age spent a large time in playing in unhygienic areas; showed increased rates of different trauma and infections, which may predispose to many neurological disorders; and because of a lack of clubs in this poor area.

On the other hand, the second highest prevalence of the included neurological disorders among females $(7.5 \%)$ was recorded in the age group 18-39 years. The risks associated with pregnancy and labor with a lack of health services available to pregnant women, especially prenatal, perinatal, and immediate postnatal, as well as hormonal contraceptive and its side effects, may help to explain the increased frequency of neurological disorders among female subjects in this age group.

It was found that $1,442(4.3 \%)$ subjects presented with one neurological disorder and $109(0.3 \%)$ had more than one neurological disorder (two neurological disorders were recorded among 83 [0.2\%] of subjects; three neurological

Table 2 Number of neurological disorders in subjects of different ages in Al Quseir, Red Sea Governorate, Egypt

\begin{tabular}{|c|c|c|c|c|c|c|}
\hline & \multirow{2}{*}{$\begin{array}{l}\text { Population } \\
\text { N (\%) }\end{array}$} & \multirow{2}{*}{$\begin{array}{l}\text { Total } \\
\text { subjects } \\
\text { n (\%) }\end{array}$} & \multicolumn{4}{|l|}{ Subjects with } \\
\hline & & & $\begin{array}{l}\text { I neurological } \\
\text { disorder } \\
\text { n (\%) }\end{array}$ & $\begin{array}{l}2 \text { neurological } \\
\text { disorders } \\
\text { n (\%) }\end{array}$ & $\begin{array}{l}3 \text { neurological } \\
\text { disorders } \\
\text { n (\%) }\end{array}$ & $\begin{array}{l}4 \text { neurological } \\
\text { disorders } \\
\text { n (\%) }\end{array}$ \\
\hline$<18$ years & $12,099(36.3)$ & $419(3.5)$ & $385(3.2)$ & $20(0.2)$ & $12(0.1)$ & $2(0.02)$ \\
\hline $18-39$ years & I3,007 (39.I) & $700(5.4)$ & $683(5.3)$ & $15(0.1)$ & $2(0.02)$ & $0.0(0.0)$ \\
\hline 40-59 years & $6,070(18.2)$ & $244(4.0)$ & $223(3.7)$ & $17(0.3)$ & $3(0.05)$ & $\mathrm{I}(0.02)$ \\
\hline $60+$ years & $2,109(6.3)$ & $168(8.0)$ & $|3|(6.2)$ & $31(1.5)$ & $5(0.2)$ & I (0.05) \\
\hline Total & $33.285(100.0)$ & $|, 53|(4.6)$ & $\mathrm{I}, 422(4.3)$ & $83(0.2)$ & $22(0.07)$ & $4(0.01)$ \\
\hline
\end{tabular}


disorders were recorded among 22 [0.07\%]; and four subjects $[0.01 \%]$ presented with four or more neurological disorders). These results are in agreement with the findings of El Tallawy et al, in Egypt's Al Kharga district, finding 346 $(0.55 \%)$ subjects suffering from two neurological disorders and $98(0.16 \%)$ with three. ${ }^{7}$ However, the explanation for the increased frequency of two or more neurological disorders concomitantly in this study could be attributed to the fact that the highest prevalence of the included neurological disorders was recorded among elderly ( $\geq 60$ years), an age group which is more vulnerable to the development of different neurological disorders, such as dementia, Parkinsonism, epilepsy, and stroke.

\section{Conclusion}

Fifteen neurological disorders were screened in a door-todoor survey project in Al Quseir, Egypt, yielding a prevalence of $4.6 \%$ (1,531 subjects). Of these, 1,422 subjects ( $4.3 \%)$ had one neurological disorder and $109(0.3 \%)$ had two or more neurological disorders.

\section{Acknowledgments}

This study was conducted in Al Quseir, Red Sea Governorate, Egypt, in collaboration with Assiut University Hospital and Al-Azhar University Hospital (Assiut branch) and the neurology departments of Sohag and Qena Universities.

\section{Disclosure}

The authors report no conflicts of interest in this work.

\section{References}

1. Neurological Disorders, Public Health Challenges. Geneva: World Health Organization; 2006.

2. Bergen DC; World Federation of Neurology Task Force on Neurological Services. Training and distribution of neurologists worldwide. J Neurol Sci. 2002;198:3-7.

3. Bermejo F, Gabriel R, Vega S, Morales JM, Rocca WA, Anderson DW; Neurological Disorders in Central Spain (NEDICES) Study Group. Problems and issues with door-to door, two-phase surveys: an illustration from central Spain. Neuroepidemiology. 2001;20:225-231.

4. Del Brutto OH, Idrovo L, Santibáñez R, et al. Door-to-door survey of major neurological diseases in rural Ecuador - the Atahualpa Project: methodological aspects. Neuroepidemiology. 2004;23:310-316.

5. Picot MC, Baldy-Moulinier M, Daurès JP, Dujols P, Crespel A. The prevalence of epilepsy and pharmacoresistant epilepsy in adults: a population-based study in a Western European country. Epilepsia. 2008;49:1230-1238.

6. Gaber SM, Aly SM, Masood KA. Center of Information and DecisionMaking, Red Sea Governorate Achievement Index. Secretary General of Red Sea Governorate; 2010. Arabic.

7. El Tallawy HN, Farghaly WM, Metwaly NA, et al. Door-to-door survey of major neurological disorders in Al Kharga District, New Valley, Egypt: methodological aspects. Neuroepidemiology. 2010;35:185-190.

8. Gourie-Devi M, Gururaj G, Satishchandra P, Subbakrishna DK. Prevalence of neurological disorders in Bangalore, India: a community-based study with a comparison between urban and rural areas. Neuroepidemiology. 2004;23:261-268.

9. Das SK, Biswas A, Roy T, et al. A random sample survey for prevalence of major neurological disorders in Kolkata. Indian J Med Res. 2006;124:163-172. 


\section{Supplementary figure}

\section{Neuroepidemiological studies in Al Quseir city}

\section{Screening sheet}

1. Does/did the child suffer from delays in mental functions such as smiling, identifying the face of the mother, or learning to speak?

2. Does/did the child suffer from delays in motor development, such as sitting, crawling, standing, or walking?

3. Have you ever lost consciousness?

4. Do you suffer from neurological seizures associated with lessened awareness?

5. Do you experience involuntary movements (jerking) in any part of the body?

6. Do you suffer from a sleep disorder or experience involuntary movement or urination during sleep?

7. Do you suffer from sudden partial or complete loss of sight in one or both eyes, double vision, relaxation of the eyelid, or the inability to close one or both eyes?

8. Do you experience the sensation of sudden, unexplained aromas?

9. Do you suffer from hearing loss or dizzy spells?

10. Do you have difficulty chewing or swallowing food? If yes, is there reflux of water from the nose?

\begin{tabular}{|l|l|l|l|l|l|l|l|}
\hline Never Rarely Occasionally Often Very often \\
\hline
\end{tabular}


11. Does the subject demonstrate speech difficulties/problems or failure to understand what is being said around him/her (to be answered by informant)?

12. Do you suffer from weakness or heaviness in any of the four limbs?

13. Do you suffer from problems in the performance of precise tasks such as typing on the computer, sewing, holding a hair comb, or using scissors, a knife, or a spoon?

14. Do you experience difficulty walking, repeated falling while walking, or ataxia while walking?

15. Do you suffer from slow movements or feeling frozen during movement?

16. Do you suffer from numbness, anesthesia, or pain in the face, limbs, or any other part of your body?

17. Do you feel like the ground is moving under your feet while walking, experience problems walking in dim light, or experience balance problems when your eyes are closed?

18. Do you have problems controlling urination or defecation?

19. Do you have difficulty dressing, combing your hair, or getting up from a sitting position (eg, on the ground or on the toilet) to a standing position (with no sense of pain in the knees)?

Figure SI Neurological disorder screening questionnaire.

\section{Publish your work in this journal}

Neuropsychiatric Disease and Treatment is an international, peerreviewed journal of clinical therapeutics and pharmacology focusing on concise rapid reporting of clinical or pre-clinical studies on a range of neuropsychiatric and neurological disorders. This journal is indexed on PubMed Central, the 'PsycINFO' database and CAS.
The manuscript management system is completely online and includes a very quick and fair peer-review system, which is all easy to use. Visit http://www.dovepress.com/testimonials.php to read real quotes from published authors. 